\title{
Thyroiditis, secondary to viral infection
}

\author{
Husnia Marrif* \\ Department of Pharmacology and Toxicology, College of Pharmacy and Health Sciences, Ajman University of Science and Technology, Fujairah, United Arab Emirates \\ ${ }^{*}$ Correspondence: husnia.marrif@mail.mcgill.ca
}

Thyroiditis is an inflammatory condition of the thyroid gland. It has been reported that thyroiditis is currently ranked the third autoimmune disease in the United States and has a staggering estimated prevalence of 21.8/100,000 (Burek et al., 2009). This is a well-established condition and many aspects of its etiology are also well known. According to the 2005 data of the American Thyroid Association, thyroiditis is classified into four types: classical autoimmune Hashimoto's thyroiditis, postpartum thyroiditis, painless thyroiditis, and thyroiditis induced by treatment with certain drugs such as interferon or amiodarone. Thyroiditis is usually associated with no symptoms. The inflammatory process is the main reason for the consequent hypothyroidism or Hyperthyroidism. Slow and chronic inflammation can lead to typical hypothyroidism, while an acute and destructive inflammation can produce acute thyrotoxicosis.

The rise in incidence and prevalence of thyroiditis associated with viral diseases such as hepatitis $\mathrm{C}$ virus (HCV) infection in some parts of the world demands special attention for further research. Autoimmune thyroiditis can be triggered by the virus or drugs used in viral treatment and immune system reactions. For instance, interferon therapy triggers autoimmune reactions and many studies showed an elevation of anti thyroid antibodies with such therapy.

Only a few studies in the literature have investigated the mechanism by which $\mathrm{HCV}$ induced thyroiditis. Among these is a study by Akeno et al. (2008). The authors detected the presence of $\mathrm{HCV}$ receptor CD81 mRNA and protein in primary cell culture of human thyroid cells. This observation suggests a direct viral infection of thyroid cells as CD81 is an essential protein for entry or attachment of HCV. Moreover, when the authors incubated glycoprotein E2 from the HCV envelop with thyroid cell culture, they observed the binding of the viral protein to thyroid cells and the release of the pro-inflammatory mediator IL-8. IL- 8 is one of the most important cytokines and is a key inflammatory mediator in viral infection. This study thus provided an explanation for how HCV could produce thyroiditis. Whether manipulating the induction of IL- 8 in thyroid cells and/or the CD 81 binding site could affect the development of thyroiditis remains to be determined. While the realm of thyroidology has seen a wealth of epidemiological studies on viral thyroiditis, lack of sufficient molecular studies in this field is clearly an issue. More studies are required to confirm Akeno et al's results and such studies will undoubtedly enhance our understanding of thyroiditis.

\section{REFERENCES}

Akeno, N., Blackard, J. T., and Tomer, Y. (2008). HCV E2 protein binds directly to thyroid cells and induces IL-8 production: a new mechanism for $\mathrm{HCV}$ induced thyroid autoimmunity. J. Autoimmun. 31, 339-344.

Burek, C. L., and Talor, M. V. (2009). Environmental triggers of autoimmune thyroiditis. J. Autoimmun. 33, 183-189.

Received: 10 December 2010; accepted: 11 December 2010; published online: 27 December 2010.

Citation: Marrif H (2010) Thyroiditis, secondary to viral infection. Front. Endocrin. 1:10. doi: 10.3389/ fendo.2010.00010

This article was submitted to Frontiers in Thyroid Endocrinology, a specialty of Frontiers in Endocrinology.

Copyright (c) 2010 Marrif. This is an open-access article subject to an exclusive license agreement between the authors and the Frontiers Research Foundation, which permits unrestricted use, distribution, and reproduction in any medium, provided the original authors and source are credited. 